Archived version from NCDOCKS Institutional Repository http://libres.uncg.edu/ir/asu/

Davison, E. L., \& Hansell, T. S. (2014). Establishing Documentary Production Support for $21^{\text {st }}$ Century Campuses Education and Information Technologies, 19(1):227-237. (March 2014) (ISSN: 1573-7608) The final publication of record is available at Springer via http://dx.doi.org/ 0.1007/s10639-012-9202-3

\title{
Establishing Documentary Production Support For 21st Century Campuses
}

\author{
Elizabeth L. Davison \& Thomas S. Hansell
}

\begin{abstract}
As a response to the growing trend of academic assignments that involve some type of video production, this paper advocates that campuses need to provide instructional as well as technical support for such projects. Universities invest in writing centers to help cultivate writing skills because they understand that providing the latest word processing programs doesn't ensure students become better writers. Similarly, students with flip/cell video cameras and editing software are not likely to produce quality projects without guidance and thus need a similar network of support for these 21st century forms of communication. This paper presents a model for offering documentary services to entire campus communities - including technology, technique, and pedagogical considerations that lead to educational film productions with strong academic content and integrity.
\end{abstract}

\section{Introduction}

Institutions of higher education are charged with preparing students to meet new challenges and demands of our times. In today's fast paced Internet driven informational world, students need to learn how to effectively communicate in a multimedia world. Students need to learn how to access and critically evaluate digital information, and how to contribute multimedia content from their discipline (Lippincott 2007; Thoman and Jolls 2004). To meet these new educational demands of the 21st century, Appalachian State University, a comprehensive university of 17,000 located in western North Carolina, initiated a documentary service program to provide students and faculty technical and instructional support for documentary research

\section{Justification of services}

Just as textbooks, newspapers and class webpages have become increasingly multimedia, so too are class assignments (e.g., Hilton 2011; Dunsmore and Lagos 2008; Lin and Polaniecki 2009; Miller 2009; Xu et al. 2011). At our institution instructors are asking students to produce webpages, audio/visual presentations or film clips to illustrate concepts, issues, findings, policies, and theories. In response to the surge in multimedia assignments, we agree with Jenkins et al. (2006) that educational institutions 
should encourage these emerging forms of communicating content, while offering guidance so that projects can be enhanced and free of legal issues. We believe, given the transition to multimedia assignments that are emerging in the 21st century, Institutions of Higher Education have a choice of standing passively by and letting students create assignments without management or take a proactive approach in steering students to produce meaningful and ethically sound productions. To see the results of inaction and lack of instruction, one can find tens of thousands of examples on YouTube of poorly produced class projects. These videos are substandard quality because they do not advance knowledge on their topic, are void of structure and rely too heavily on copyrighted material lifted from the Internet. The point of this article is to suggest that to the extent colleges and universities have writing centers to assist students in cultivating their written communication skills, colleges and universities should also provide multimedia communication skills assistance.

One of many forms of multimedia scholarly expression is documentaries. John Grierson, one of the pioneers of the form, defined documentary as "the artist representation of actuality" (Aufderheide 2007). Documentary work offers students an opportunity to put their research, knowledge, and skills into a multi-media platform. Documentary productions require many skills including researching, writing, critical thinking, creativity and effective communication. On our campus we have witnessed a growing desire among faculty and students to engage in documentary work, but find many lack the necessary skills and modus operandi to produce documentaries.

With recording devices such as cell/flip cameras readily accessible and basic editing programs standard on most computers, the need for documentary instruction is crucial. Students need more than technology to create documentaries. Students do not become better writers because the university offers the latest word processing programs, and faculty and students will not learn effective ways to generate and share multimedia works without a support network in place to discuss the tools, skills and processes.

Our documentary service program teaches, engages in, and presents documentary work grounded in collaborative local and global partnerships that use photography, film/video, audio, and narrative writing to capture and convey memory, life, research, theory, and culture. The mission of our program is to promote scholarly documentary projects across campus. We do not offer courses or institutional course credit, but provide support for faculty, staff, and students to engage in documentary work. We have worked with faculty from more than a dozen academic programs who incorporated scholarly documentaries in their regular courses as creative outlets for scholarship and who recognized that the process of learning and expression of knowledge has evolved beyond the book and the blackboard.

\section{Addressing the trend}

In 2008, Appalachian State University launched University Documentary Film Services to aid faculty in incorporating short documentary projects into traditional courses. In this article we explain our services in hopes that other institutions will consider starting a similar program. Our services offer faculty direct classroom support regardless of discipline. We visit participating classes one to three times a semester based on need. Our classroom visits provides instructions on (1) how to research \& structure the documentary, (2) basic recording and interviewing skills and 
(3) instruction on editing and copyright issues. While many of today's students have computer skills that aide them in quickly learning the technical skills needed to produce a documentary, more assistance is needed to guide content.

While there is much debate about the boundaries between documentaries, film, and reality TV (e.g., Cowie 2011), we advocate for students to engage in scholarly documentary work. Like a quality research paper, a strong documentary project will advance knowledge about the topic with a presentation that is clear, organized, cohesive and compelling (Worsnop 1996). Each documentary project should reflect a general knowledge of the subject based on extensive research of the topic as well as new discoveries in the form of narration, interviews and stories. Similar to any research paper, the documentary projects should explore issues further; provide analysis, comparison, contrast and critical thinking. The documentary projects need to be well structured and technologically smooth.

\section{The production process}

An overly simplified way to explain the documentary production we are proposing is to think of the documentary project as a visually illustrated research paper. There are a range of documentary project prototypes from high tech to low tech. Low tech projects emphasize writing the informative narration, and then illustrating the script with carefully selected images. Voice-over-stills featured in the model created by the Center for Digital Story Telling is a good example or a historical project that accesses archival footage. A higher tech production also involves extensive research, but requires a more far-reaching production process. These productions often involve scripts, original footage and images, multiple interviews and more complex video editing. The low-tech projects utilize software applications such as power-point, iMovie or Movie Maker in contrast to high tech projects which involve considerable editing with professional software programs such as Adobe Premiere or Final Cut.

Students begin their projects by exploring their topic through traditional research avenues of reading books, newspapers and scholarly articles. Additionally, students are encouraged to have conversations with their instructors, scholars, classmates, and community members as a way of furthering understanding of their topic and as an avenue for discovering individuals with different perspectives and expertise on the topic. After carefully and fully researching their topics, students start creating a structure for their project, akin to producing an outline for a research paper. The structure includes major and sub-points to cover, sequencing, narration, list of shots (e.g., scenes, visuals), subjects to interview, and questions to ask. As with most research projects, the final project may look different from the initial structure, but students will waste less time in production if they spend more effort on the front-end thinking through the project.

After completing the initial research phase of the production, students start recording materials for their projects. With still/video cameras and/or digital audio records, students conduct interviews, film B-roll and record ambient sound for their productions. Available for free rental on our campus are consumer grade cameras, digital audio recorders, lavalier microphones, and tripods that have been purchased with educational technology funds. We also offer professional equipment for faculty and 
graduate student projects.

In our technical skills instructions, we focus on a few easy to remember best practices that greatly enhance the quality of the production. We cover topics such as camera operations, lighting, framing, sound, and interviewing techniques. We offer students equipment access, lab space, and assistance for editing. Our instructions do not include the use of light kits or other professional recording gear, instead we give tips on how to compose shots and most importantly, demonstrate the importance of keeping a shot stable.

Another bonus to carefully planned productions is that students are less likely to overshoot materials. For high tech productions we recommend students record around $1 \mathrm{~h}$ of material for a 5 min production. The last stage, post-production, includes editing which is an important process to support and is discussed more in-depth later in the article. We encourage students to submit several drafts of their project in the course of the semester.

In addition to the final document, we suggest students turn in their outlines, bibliography and a perhaps a reflection paper about the project. We also recommend students turn in a copy of their narration so that instructors can subject the text to plagiarism checks, if needed, as with any paper.

\section{Ethical and legal issues}

An important consideration for any documentary work is copyright. If you look to YouTube for examples of class projects, you will see a lot of productions that include illegal use of images, footage and especially music. Students are skilled at grabbing materials from the Internet, but the majority of online resources are not copyright free (Center for Social Media 2008). Without guidance, students are less likely to pay attention to the ethical and legal ramifications of their work. "In a world in which the line between consumers and producers is blurring, young people are finding themselves in situations that no one would have anticipated a decade or two ago....young people are discovering that information they put online to share with their friends can bring unwelcome attention from strangers" (Jenkins et al. 2006:16-17).

We instruct students to be copyright mindful. The easiest way to create a documentary project free of copyright violations is to record original material (e.g., audio, photos and video). Alternatively, our website provides a list of sites offering free music and photos. We also encourage students to conduct Internet searches with the terms Open Source and Creative Commons. For historical topics, we point them to the Library of Congress digital collections.

Another legal consideration is the release form. People appearing in student documentaries must sign an official university release form granting the student and university permission to use their images and voices in the production and for posting on the Internet. We widely distribute the release form and make it available to print from our website.

Our institution has agreed that most undergraduate documentary projects do not need reviewing or approval from our Institutional Review Board (IRB). We have 
made the case that most documentary interviews conducted by undergraduates offer only anecdotal evidence as opposed to the empirical evidence that is officially classified as "research" by the IRB. The fact that most undergraduate projects do not involve a systematic collection of data for use in generalizations of results is another reason these projects are considered exempt. Signed release forms of documentary subjects guarantees informed consent of the participants which is a key part of ethical research practices.

\section{Editing}

The most challenging area of our services is supporting editing. Unless there are facilities on campus for students to capture their media, instructions on how to edit and staff assistance for help with editing, the documentary projects are going to be lessons in technological frustrations. That said, we see an increasing number of students who have learned to edit in middle or high school. We anticipate, 5 to 10 years from now, that most college students will arrive on campus with basic editing skills. Those of us who have been teaching over the past couple of decades remember having to instruct college students how to browse the web or create power-point slides, applications that now seem instinctive to students.

For editing software we recommend supporting both PC and Apple users. We teach basic editing techniques on an intermediate software program, but encourage students to use whatever editing program they are comfortable with or have access to. The disadvantages with beginning editing programs like iMovie or Movie Maker, standard on most consumer computers, is that they only allow for one video track which makes standard documentary editing practices such as cut-aways more challenging. Intermediate programs are widely available for PCs, but less so for Apple. Most students, for the sake of the convenience, choose to create their documentary projects using the beginning editing programs on their own personal computers. Although we do not push students to choose one software over another, we make sure they are taught the basic editing skills (e.g., timeline, trimming clips) and are aware of their options. Students regularly request editing support after hours at night and on weekends.

\section{The importance of content}

The primary reasons universities should consider having documentary support services is to improve content of typical student productions. When we give presentations about incorporating documentary production into the classroom, we start by showing a couple of really bad examples found on YouTube. Videos that may on the surface appear flashy and technically slick often are void of content and do not advance knowledge on the topic. These lackluster productions let illegal use of copyrighted song lyrics and images do all the work and often have failed to add any educational value to the productions.

As an alternative, our services guide students and faculty in creating documentaries that reflect new discoveries on the topic in the form of narration, interviews and stories. Similar to any research paper, documentary projects should explore issues further; provide analysis, comparison, contrast and critical thinking. Quality productions are 
structured and technologically void of major audio or video glitches.

Interestingly, we find many faculty are still new to the multimedia world and are bedazzled by student projects that look good, have catchy music and above all, work. A documentary support center helps instructors ensure that multimedia projects go beyond the bells and whistles and include scholarship and structure. The goal is for students to learn about their topic while producing the documentaries and for viewers to actually gain knowledge about the subject by watching the documentaries. Just as a well written paper with proper grammar and sentence structure may be pleasant to read, but lack substance, we must look at documentary projects with the same critical eye. Students and instructors should apply their analytical skills to these projects. Documentary projects need the same guidance, analysis and feedback as with any classroom assignment. Instructors need to avoid being blinded by technological glitter of videos and ensure the documentaries are making contributions to the field and/or to the students' education on the topic.

\section{Best practices}

Our model for documentary projects is for students to produce a 5 min video project. Although like any assignment, not all projects are worth saving, the goal is to maximize projects that are worthy enough to archive and distribute. We recommend that for quality documentary productions the projects should become the class centerpiece. The reality is that students will spend more time outside of class working on their documentary productions than writing a paper and they want credit for their efforts. More importantly, these projects require close guidance and classroom time for feedback. Bottom line, for quality productions, instructors need to allow time for students to check-in and to keep them on track throughout the semester. We find that classes producing the better projects have clear deadlines of outlines and drafts as well as allow class time for pitching ideas and watching multiple drafts.

The success of documentary projects depends on both the instructors and students taking ownership in the project. Ownership is fostered by having a project that makes a difference for some agency or organization or contributes knowledge to the field. Because of the guidance, as well as the class time needed to view drafts and final cuts, we recommend incorporating projects into classes of 30 students or less. We also recommend that students pursue these projects on their own or with a minimum of one or two partners. Any group project with three or more members is subject to typical group dynamics of free riders and scheduling conflicts.

Above all, it is paramount that instructors take class time to review drafts. In producing the first draft, students gain a realistic expectation of the time needed for production. Just like writing, we cannot expect greatness from students who turn in one draft; the same is true for documentary projects. Turning in drafts at least two to three weeks before the final is due forces students to avoid procrastinating on the project until there isn't enough time to adequately complete the assignment. Also, we are pleased with the collegial feedback students offer each other while viewing drafts. Finally, we encourage students to incorporate at least three interviews in their 5 min productions in order to provide different perspectives on the issue they choose to investigate. Although students initially think $5 \mathrm{~min}$ is too little time for their projects, we feel it is an optimal time limit for the typical class productions. Just like many undergraduate research papers often start to ramble after a few pages, so do 
documentary projects. The 5 min forces students to have a clear research outlook and to make tough, but good choices in the editing process.

\section{Dissemination}

Distributing quality productions to audiences beyond the end of the semester final project presentation is an important part of documentary initiatives. There are free ways to distribute the projects widely including posting videos on Internet sites such as YouTube, Vimeo or creating a Blogspot which allows for supplemental information about the project. The advantages of posting online are that students or instructors can easily send the links to others including individuals appearing in the video, organizations, or anyone perceived interested in viewing the documentary. This is much easier than mailing copies of a DVD.

We like Blogspot because the video can be nested in a webpage with supporting documentation such as bibliography, reflections on the project or more details about the project. YouTube is a great source for sharing drafts. Instructors can create a channel for their classroom with privacy settings such that only class members have access to the videos. This allows students to post their videos as well as provide feedback on classmates' projects.

The disadvantage of YouTube, Blogspot, Vimeo and other public sites is that the students have ultimate control over the project and link. The student can decide to delete the posting at any time, prohibiting an instructor from accessing the work in the future. As a work around, we developed a university webpage template that allows students to post their video with supporting text. This requires university server space and a bit of programming to develop the webpage template. However, the webpage template allows us to keep the quality projects and delete the poor productions. The end of the semester presentations of the documentary projects go smoother when students show them from the webpage instead of having to wait to load their DVDs in the classroom. Finally, colleges are increasingly adopting portfolio software to showcase student work to future employers. We anticipate documentary projects be an important part of portfolio materials.

\section{Feedback}

We asked instructors that worked with University Documentary Film Services staff to incorporate documentary production into their classes, to provide anonymous feedback about the effectiveness of short scholarly documentary projects as a learning tool. We sent out an email announcing the online survey to 29 university instructors that we have worked with over the last 2 years. The online survey included seven questions regarding outcomes, several open-ended questions, and was designed to guarantee anonymity. Seventeen instructors completed the survey for a response rate of $57 \%$.

The instructors provided positive feedback about the educational value of documentary projects. We asked instructors to rate seven educational outcomes on a seven-item scale. Higher scores indicated increased learning through the documentary projects. Results of the 7 outcomes are seen in Chart One. On average, all instructors found the documentary projects to increase students' skills and knowledge. 
The strongest outcome from the projects (item with the highest score) is engagement followed by ability to communicate in a multimedia world.

Next, we computed a scale combining all seven factors (cronbach's alpha reliability score of .842) with possible scores ranging from 7 to 49 . Analysis of the scale shows scores ranged on the high/positive end (from 37 to 49) with a similar mean (44) and median (45) and a standard deviation of 4 points. Instructors strongly feel students increase both knowledge and skills in all areas.

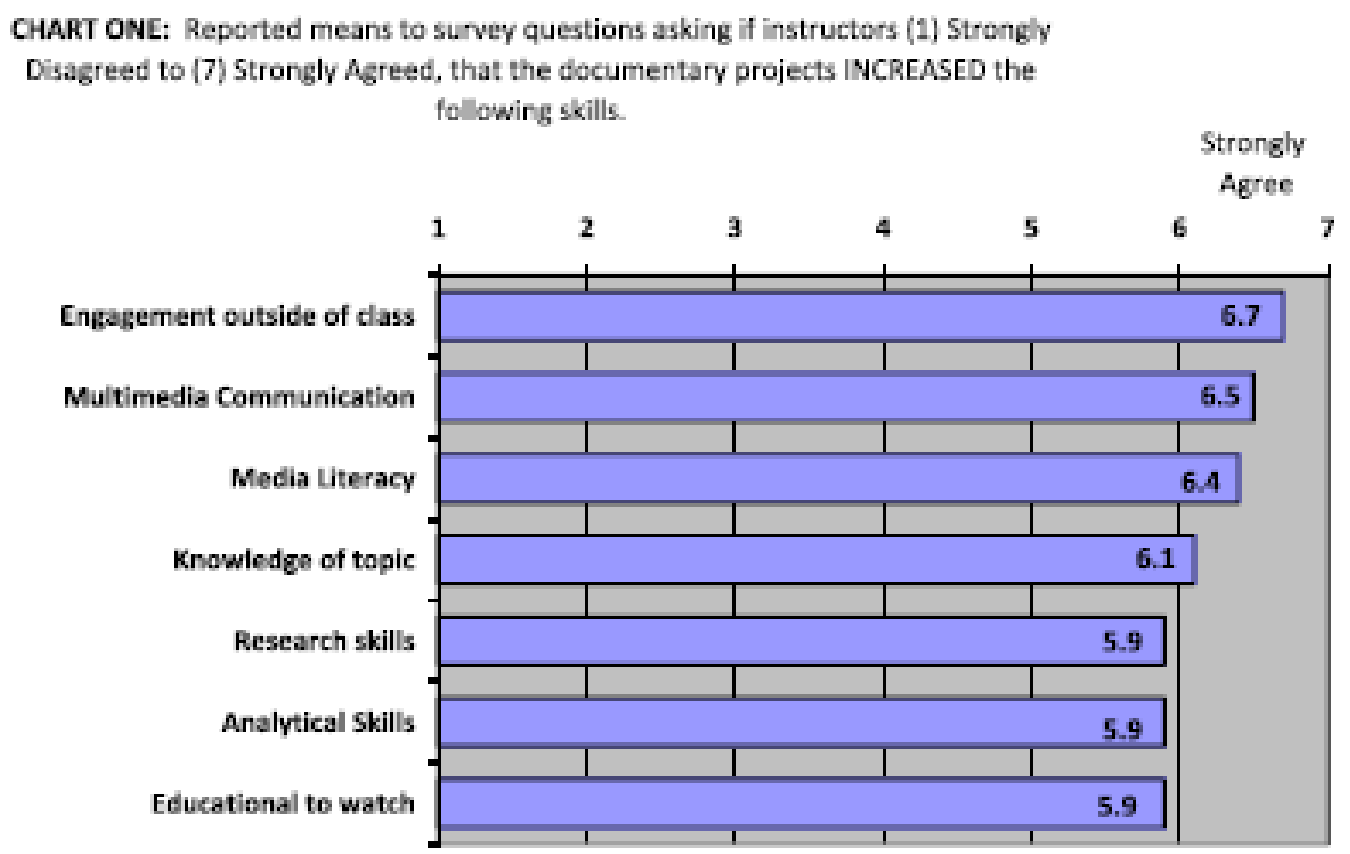

When asked to comment on strengths of the documentary projects, instructors appreciate that the documentary projects allowed students to move outside the traditional learning styles and the opportunity for students to produce something to be proud of at the end of the semester. The instructors found the projects to engage students in more meaningful ways than standard research papers. Below are a few quotes from instructors reflecting on the strengths of these projects.

"These projects allow students to act like scholars. More specifically, it allows students to present their work to audiences - just like scholars do. In fact, for a college student, it's about as close to publishing in a peer reviewed journal as they are likely to get."

Projects increase "depth of understanding of topic, learning to collaborate in groups, developing very important interpersonal, research, and technical skills." "Students enjoy them. They incorporate a kind of real-world writing that many students will do in the professional lives. They enable students to accomplish rhetorical goals that the written word alone does not enable." 
When asked to report on weaknesses of these academic projects, most comments directed weaknesses toward students' failures and not toward the projects themselves. Reported weaknesses included time management skills and ability to structure work outside of class to complete the tasks in a timely manner. Other comments, addressed the time commitment and technical learning curve that many students confront in producing their projects.

Instructors reported that students' number one complaint about the documentary projects seem to be "although they were warned, they were amazed at the amount of time needed to complete a quality project." There were other mentions of technological, especially editing, challenges and the typical frustrations of working in groups.

We asked instructors to reflect on how the documentary projects compared to standard research papers. Instructors responded, "they are much more interesting for the students and the faculty member as a learning tool." A common comment was the fact that grading documentary projects is a more pleasant task than grading papers. Engagement level is a prominent part of documentary projects. "No comparison. Students can fake 'engagement' in a research paper. They can't on this project. They are engaged or the project doesn't get done."

Almost all of the instructors said they would use the documentary assignments again. Only two reported they were unsure and no one said they would not repeat the assignment. When asked what they would do differently with the documentary projects, instructors' comments dealt more with their management of the projects with suggestions such as starting earlier and requiring more drafts or benchmark assignments.

Finally, On a 7-point scale of how helpful University Documentary Film Services was for the success of the classroom projects, with 1 as "Very Helpful" and 7 as "Less Helpful," the mean score was 1.3 and the median score a 1 "Very Helpful." The University Documentary Services receives high praise for classroom assistance with the assignments.

\section{Conclusion}

The educational landscape is changing and so must academia evolve to accommodate the new pedagogical shifts in learning and communicating. In the age of Facebook and YouTube, students connect to information in ways that did not exist 20 years ago. A recent Pew Internet \& American Life Project study reports that many teens have already shared online content they created (Lenhart et al. 2010). On their own or in school, young people are expressing themselves beyond the traditional modes of oral or paper communications. These numbers will only increase as students continue to enhance their multimedia skills and as technological advances eases the ability to produce multi-dimensional content.

Appalachian State University's nascent documentary service program is an example of meeting the educational demands of the 21st century. Most college courses have students work on writing skills in addition to the course content. We advocate that students also need opportunities to cultivate their multimedia skills (Thoman and Jolls 2004). By working on short scholarly documentary projects, students learn 
technical skills as well as gain an understanding of best practices in communicating important content from their field. Akin to a university writing center's mission to help develop student writing, documentary services seeks to assist students in their multimedia communication skills.

Short documentary projects allow for student resourcefulness and engagement that are not always seen in other assignments. We find students are very creative in dramatizing the real and presenting abstract information. On our campus we have seen documentary projects help students make local to global connections, forge community partnerships, learn basic productions skills, as well as explore unexamined privileges and relationships. By conducting interviews for their productions, students are forging important connections beyond the brick and mortar of academic buildings.

We use feedback from an anonymous survey of instructors to gauge the effectiveness of documentary projects in meeting the learning objectives discussed in the article. Results provide strong evidence that instructors find these projects increase engagement, media literacy, research and analytical skills in the classroom experience. The instructors state they enjoy the uniqueness, educational, innovative and creative quality of the projects.

Exposing students to media production processes helps increase their media literacy by teaching them the principled and methodological decisions that go into multimedia communication (Lin and Polaniecki 2009). Schwarz and Brown (2005:p 6) writes that while there is lack of agreement about the concept of media literacy, "... many scholars, educators, parents, and community activists agree that media literacy is essential in the 21st century." Most scholars agree that being able to produce, analyze and critique various media is an important part of media literacy competence (Schwarz 2005; Thoman and Jolls 2004)

We encourage post-secondary institutions to offer documentary support services as resources permit. A short list of the basic technological resources needed includes knowledgeable staff of documentary production; recording equipment for students to check out including consumer grade cameras, tripods, lavalier microphones; computer editing labs with firewire ports, intermediate level editing software, studio microphones for narration, and extra backup storage space for projects.

Finally, we are impressed with the range of learning that goes on behind the scene, that is, beyond what is actually viewed in the final project. Some of our students have run into technological glitches and others have lost footage. However, by getting out of the library and classroom buildings to conduct interviews, they are gaining more indepth knowledge about their topic above what they attain in books or articles. Even if an interview doesn't make the "cut" in the editing room it has left an impression.

In sum, we recommend that at some point in their college careers, students produce a short (around $5 \mathrm{~min}$ ) scholarly documentary project. We have suggested some basic steps to consider for implementing a documentary service program to assist students in these endeavors. We are not suggesting these services replace documentary courses that offer students a history of the discipline and an in-depth exposure to techniques and subject development. Instead, we advocate offering campus support to standard classes, across disciplines, in the course of a regular semester. Documentary support 
services assists students in moving from being mere consumers of media, to being creators of multimedia content.

\section{References}

Aufderheide, P. (2007). Documentary film: A very short introduction. Oxford: Oxford University Press.

Center for digital story telling. www.storycenter.org

Center for Social Media (2008). Code of best practices in fair use for online video, American University retrieved January 9, 2012 from, http://www.centerforsocialmedia.org/fair-use/relatedmaterials/codes/ code-best-practices-fair-use-media-literacy-education

Cowie, E. (2011). Recording reality, desiring the real (visible evidence). Minneapolis: University of Minnesota Press.

Dunsmore, K., \& Lagos, T. (2008). Politics, media and youth: Understanding political socialization via video production in secondary schools. Learning, Media, and Technology, 33(1), 1-10.

Hilton, G. (2011). Rehearsing for an audience: Students learning science through video production. International Journal of Innovation and Learning, 9(3), 311-324.

Jenkins, H., Puroshotma, R., Clinton, K., Weigel, M., \& Robison, A. J. (2006). Confronting the challenges of participator culture: Media education for the 21st century. The MacArthur Foundation retrieved January 9, 2012 from, http://www.newmedialiteracies.org/files/working/NMLWhitePaper.pdf

Lenhart, A., Purcell, K., Smith, A., \& Zickuhr, K. (2010). Social Media and Young Adults. Pew Internet: Pew internet \& American life project. Retrieved August 16, 2011 from, http://www.pewinternet.org/Reports/2010/Social-Media-and-Young-Adults.aspx

Lin, C., \& Polaniecki, S. (2009). From media consumption to media production: Applications of YouTubeTM in an eighth-grade video documentary project. Journal of Visual Literacy, 28(1), 92-107.

Lippincott, J. K. (2007). Student content creators: Convergence of literacies. Educause Review, 42(6), 16-17.

Miller, M. V. (2009). Integrating online multimedia into college course and classroom: With application to the social sciences. MERLOT Journal of Online Learning and Teaching, 5(2), 395-423.

Schwarz, G. (2005). Obstacles, challenges, and potential: Envisioning the future. In G. Schwarz \& P. Brown (Eds.), Media literacy: Transforming curriculum and teaching (pp. 229-250).

Malden: National Society for the Study of Education. 
Schwarz, G., \& Brown, P. (2005). Media literacy: Transforming curriculum and teaching. Malden: National Society for the Study of Education.

Thoman, E., \& Jolls, T. (2004). Media literacy-A national priority for a changing world. American Behavioral Scientist, 48(18), 29-29.

Worsnop, C. (1996) Using rubrics to assess media work in the classroom. Ontario, Canada: MediaAwareness Network. Retrieved December 30, 2011, from http://www.mediaawareness.ca/ english/resources/educational/teaching_backgrounders/media_literacy/using_rubrics.cfm

Xu, Y., Park, H., \& Baek, Y. (2011). A new approach toward digital storytelling: An activity focused on writing self-efficacy in a virtual learning environment. Educational Technology \& Society, 14(4), 181-191. 